\title{
Pata de palo y guantes de seda: mujeres piratas en el cine
}

\author{
Virginia Guarinos, Inmaculada Gordillo, \\ Ma Mar Ramírez, Francisco Javier López y Fátima de los Santos \\ Universidad de Sevilla \\ http://dx.doi.org/10.12795/AdMIRA.2017.01.02
}

Nada hay más cierto que afirmar que la piratería es cosa de hombres. Tampoco nada tan cierto como que siempre ha habido mujeres arriesgadas que se han adentrado en estos territorios masculinos para desarrollar su actividad, normalmente peligrosa. El cine, como reflejo de la sociedad, procura incluir en sus historias estereotipos procedentes de la vida empírica. Así, hoy por hoy se pueden encontrar múltiples personajes cinematográficos femeninos dedicados a oficios de hombre, tendiendo a veces a un proceso de "machificación", que se ha generado en el cine paralelo al de la dulcificación de ciertos hombres con la pretensión de satisfacer las reclamaciones sociales que desean papeles igualitarios, pero queda mucho por hacer. Y aunque la Teniente O’Neill no sea un prototipo deseable de personaje femenino en roles masculinos, bien es cierto que la representación de la mujer en la piratería lejos de ser un reflejo reivindicativo, si se observa, no pasa de ser una representación patriarcal más, al puro estilo del cine clásico y su utilización fetichista del personaje femenino, cuestión que no se ha solucionado desde las primeras mujeres piratas del celuloide hasta la última, en Piratas del Caribe en cualquiera de sus tres entregas (Gore Verbinski, 2003, 2006 y 2007). Nos referimos al cine de Hollywood, puesto que estas películas suelen ser de alto presupuesto y normalmente otros cines nacionales periféricos no suelen abordarlas, ya que ni siquiera producen películas de época por sus elevados costes de producción. Reflexionaremos sobre las mujeres piratas y su construcción como personajes en una historia de hombres, dirigidas y guionizadas por hombres y pensadas para un espectador también hombre.

\section{Mujeres piratas en la historia}

La historia de la piratería es de por sí muy antigua y ha dado lugar a innumerables relatos reales y de ficción trasladados después a las pantallas. Aunque suele atribuirse al término los sinónimos de corsario, filibustero o bucanero, el caso es que la palabra proviene del griego peiratés que, en su origen, significa aventurarse, el que se aventura 
o el que busca fortuna. Los historiadores señalan que la figura del pirata aparece en el momento mismo en el que las embarcaciones contaron con una calidad suficiente para surcar el mar. La realidad se mezcla en no pocas oportunidades con la fantasía y con las leyendas de hazañas de personajes rudos, diestros y osados que, en determinadas rutas marítimas, llevaban a cabo sus acciones de piratería.

Con el paso del tiempo y el descubrimiento por ejemplo de la pólvora (con lo que este avance conllevó en cuanto a nuevos armamentos y técnicas de combatir), la piratería se transforma casi en una profesión, en una filosofía. Las rutas se extienden por el Mediterráneo, el norte de Europa, Asia y África. Finalmente, el descubrimiento del continente americano, con cientos de nuevas costas por las que se movía el oro de las colonias, amplió considerablemente el escenario de acción para aquellos que se dedicaban al pillaje.

Indiscutiblemente el perfil de los piratas históricos era el de estos hombres aventureros, más o menos despiadados, que hicieron de las aventuras en los mares un estilo de vida. No son pocos los nombres que resultan familiares, todos ellos masculinos: Francis Drake, Cavendish, Morgan, el Olonés, Barbanegra o el Capitán Kidd, por recordar algunos. Sin embargo, algunas mujeres también estuvieron a la cabeza de tripulaciones, en la cúspide de esta estructura social con sus propias leyes y códigos de conducta que conformaban los piratas. Aunque en ocasiones se les confunde con mujeres-soldado, exploradoras, viajeras o incluso conquistadoras, el caso es que estas piratas se caracterizan por integrar e incluso capitanear tripulaciones dedicadas a robar cargas, pedir rescates por sus viajeros o incluso hacerlos prisioneros y muchas veces apropiarse de las naves mismas.

Mencionaremos cinco de estas figuras históricas provenientes de distintos lugares del mundo. La primera de ellas es Sida al Hurra, nacida en 1495 en un pueblo del Rif, experta en negociaciones y en asaltos a naves. Sus cualidades como estrategia la llevaron a ser, además de gobernadora de Tetuán, jefa reconocida de los piratas que rondaban las costas africanas cercanas del estrecho de Gibraltar (Arabi, 2005: 90).

La segunda es la irlandesa y reina de los piratas Grace O’Malley que se enfrentó a la Reina Isabel I y llegó a erigirse en el símbolo de la Irlanda libre. Desde pequeña había 
vivido cerca del mar, ya que su padre era jefe de un importante clan y, además, un experto marino. Se cuenta que para poder acompañarlo en uno de sus viajes a España, Grace se cortó su hermosa cabellera, de allí su sobrenombre de Gráinne Mhaol (esta última palabra significa en irlandés rapado o que lleva el pelo corto). A lo largo de más de 50 años esta aguerrida y dura negociadora mujer navegó, pirateó y comerció con sus botines. Llegó, incluso, a poseer una flota de barcos y a ser una experta. En sus diversas biografías se cuenta como incluso dio a luz al menor de sus hijos cuando su nave estaba siendo atacada (Vázquez Chamorro, 2004).

También irlandesa y experta en el uso de las sables y en el manejo de pistolas, Ann Bonny es una de las mujeres piratas más famosas de la historia. De aguerrido carácter, vivió el tránsito entre el siglo XVII y XVIII. Desheredada por su padre, vistiendo ropas masculinas, llevó una azarosa vida que la llevó por los lugares más dispares del mundo, recalando en distintas islas del Caribe. Su peligrosidad era temida y respetada en el entorno del mundo de la piratería en el cual vivió (Musnik, 2007).

Precisamente uno de los compañeros sentimentales de Ann Bonny fue un famoso pirata conocido como "Calico Jack" Rackham, quien se dedicaba a acoger a los marineros de los barcos capturados como trabajadores forzosos para el suyo propio. Así fue como conoció a un chico joven que, en realidad, era una mujer de origen inglés y de nombre Mary Read. Desde niña Mary fue obligada por sus padres a usar ropa masculina a fin de sustituir a un hermano fallecido y con esta apariencia de hombre fue como se enroló en el ejército. De allí saltó a la piratería, ambiente en el cual conocería a Ann Bonny haciéndose amigas e, incluso, compartiendo el amor de Calico Jack en una relación escandalosa en la época. La excepcional vida de ambas terminaría con la condena a la horca, ambas embarazadas y juzgadas precisamente por piratería. Read moriría de fiebres y Bonny desaparecería misteriosamente, aunque se dice que finalmente fue su padre quien la salvó de morir en la horca (Moratón, 2007: 62)1.

De los mares de China proviene una de las piratas más famosas que se conocen. Se trata de Cheng I Sao. Siendo muy joven se casó con un miembro de una dinastía de

1 La vida de ambas es reseñada en la obra de Charles Johnson (seudónimo con el que se ocultaba el escritor Daniel Defoe) titulada Historia general de los robos y asesinatos cometidos por los piratas más famosos. 
piratas más reconocidas de los mares de la China. A su muerte, Cheng asumió el mando de una flota de seis escuadrones de piratas que comandó de manera eficaz. Su principal acierto fue el de articular una extensa red de espionaje que le permitió atracar cientos de barcos que navegaban por aguas que consideraba de su jurisdicción. Incluso en su vejez dirigió una fábrica de contrabando de opio (Musnik, 2007: 125).

\section{Sirenas y Amazonas: diosas, mitos y mujeres piratas}

Dentro de la representación de la figura del pirata existen determinadas constantes que atañen a la semántica narrativa, pudiendo sintetizarse en cuatro funciones esenciales: el viaje (en barco a través de los mares), la aventura, la batalla o la búsqueda del botín. Además, desde la concepción romántica, el pirata se asocia a la libertad y al coraje. Si se contemplan los relatos de la tradición cultural de occidente, estas funciones suelen en la inmensa mayoría de los casos- estar protagonizadas por personajes masculinos. Es el hombre el que escapa del círculo doméstico y rutinario de una vida convencional y se lanza a surcar los mares en busca de libertad, aventuras y algún suculento botín que le procure su valentía, arrojo y la lucha contra cualquiera que se cruzase en su camino. Frente a ese alarde de masculinidad, las mujeres suelen estar relegadas a funciones de espera, de pasividad o de objeto de deseo. El recorrido épico que implica el viaje no es un camino habitual para las protagonistas femeninas, ni el territorio marítimo el más frecuente de sus roles tradicionales centrados, en muchos casos, en la conquista de marido. La aventura y el viaje, por tanto, no resultan las funciones más usuales para ellas. Las mujeres en la piratería no solo constituyen rara avis, sino que además son sinistra avis (pájaro de mal agüero), por lo que los marineros procuraban que no fuesen en los barcos, ni siquiera como acompañantes.

Sin embargo, las heroínas y villanas aventureras poseen representantes en el relato contemporáneo, aunque el precedente más remoto y afianzado culturalmente corresponde a los mitos y las tradiciones narrativas de la antigüedad. Hay que tener en cuenta que lo mítico es la expresión de esquemas profundos que toman formas y expresiones diversas y que permiten comprender tanto el arte generado por una determinada comunidad, como las esencias fundamentales de esa misma sociedad (Durand y Vierne, 1987: 15). 
Así, numerosas tradiciones míticas recogen la figura de una mujer poderosa y desafiante relacionada con el mar. Algunas religiones americanas procedentes de África otorgan gran importancia a la diosa del agua, denominada Oya -la representación del río Nígeren cultos como el candomblé, el umbanda y el batuque. Pero la deidad más extendida en la cultura yoruba es Yemayá, la hija de Olofi, el creador del Universo a partir del fuego. Gracias al agua -el símbolo de esta primera deidad- el mundo empezó a existir, por lo que se le considera la madre de todos los seres. Su personificación tiene que ver con los océanos, con las olas y las mareas, con la fuerza destructora del mar y su continuo movimiento. Yemayá es la dueña absoluta todo aquello que se acerque o que navegue sobre las aguas. Océanos, mares, ríos y arroyos se reúnen en ella, llevando la destrucción y el sacrificio hasta su fondo más inhóspito. Aunque es una figura justa y bondadosa, cuando se enfada resulta implacable. Además disfruta con la caza y el manejo de armas y herramientas. Como la mujer filibustera, en ocasiones se representa con un aspecto masculino y sus atributos son elementos fuertemente relacionados con el imaginario del pirata: el barco, la luna, el mar, el ancla, las estrellas, peces, redes, conchas...

Pero Yemayá no es la única figura mítica ligada al mar. Las Sirenas, en la tradición mitológica griega, eran seres fabulosos que gracias a sus cantos melodiosos atraían a los marineros, causándoles la muerte. Aunque en un primer momento en Las Metamorfosis de Ovidio se describen como seres monstruosos, las sirenas poseían un atractivo irresistible que llevaba a la perdición a los marinos, quienes encantados por sus melódicas voces estrellaban sus barcos contra las rocas. Primero fueron representados como seres alados, una mezcla entre mujer y ave, pero más adelante se impuso la apariencia de mujer hermosa con cola de pez. En época preclásica se identificaron con las Náyades, seres femeninos que representaban el agua de los ríos. Aunque bondadosas, en ocasiones podían mostrarse peligrosas, ya que se consideraba un sacrilegio bañarse en sus aguas, o simplemente contemplarlas2.

Hay que tener en cuenta que la aventura y las hazañas de los héroes suelen ligarse a lugares míticos o simbólicos, y los grandes océanos o los mares suelen formar parte de

2 Frente a las Sirenas, Náyades y Oceánides (deidades de los océanos) se sitúan las Nereidas y la Ondina (mitología germánica), deidades del mar y las aguas, aunque carentes de la agresividad y el poder destructivo de las Sirenas. 
ese imaginario: "desde la antigüedad los océanos y mares se transformaron en el límite por excelencia entre el mundo conocido y el desconocido, entre lo real y lo fantástico" (Ramírez Alvarado, 2001, 57-58). Por ello los ejemplos abundan: Neit (también llamada Net o Nuanet), una divinidad del Egipto predinástico, es la señora del mar; Sedna, un mito de las zonas árticas de Canadá, Alaska y Groenlandia, vive en los océanos como una figura terrorífica. La diosa griega del amor nacida de la espuma del mar, Afrodita, es superviviente de una tradición mítica anterior -como le ocurre a la mayoría de las deidades-, que según Husain (1997: 50) se corresponde con Asherah, la señora del mar, una diosa de Oriente Próximo. Walutahanga, de la cultura oral de Oceanía, es la diosa melanesia del mar, una figura temible y devastadora. Y dentro del folklore europeo destacan Morgan le Fay y las Morganas (ondinas de Bretaña), que toman su nombre del vocablo mor, que en celta significa mar.

Por otro lado, las mujeres guerreras abundan en la mitología clásica y en otras con raíces matriarcales. Representaciones míticas de mujeres luchadoras, conquistadoras o defensoras, con aspecto feroz enlazan con la fiereza, la valentía y el arrojo de la mujer pirata. Figuras como Epona (celta), Zaria (eslava), Dilbah (babilónica) o Anahita (zoroástrica) son diosas de la guerra; Coatlicue, "la de la falda de serpientes" era una divinidad azteca destructora. Aunque también representaba la fertilidad (como muchas diosas guerreras), reflejando la dualidad de muchas tradiciones, donde la vida y la muerte se unen en una misma figura mítica.

Palas Atenea, la diosa griega de la guerra y la estrategia, nace de la frente de Zeus completamente armada. Su madre fue la oceánide Metis, y en algunas tradiciones se narra que fue educada por el dios río Tritón, asociándose también a las aguas y los ríos. Diana, diosa romana de la caza, poseía un lado salvaje que comparte con su equivalente en la tradición griega, Artemisa. Ambas se representan con armas (un arco y flechas o una jabalina) por sus caracteres eminentemente guerreros. La diosa Kali de tradición hindú, es una diosa sanguinaria y cruel representada con la lengua entre los dientes y con sus múltiples brazos cargados de armas y trofeos de guerra como cráneos humanos, cabezas cortadas y manos amputadas. Sejmet era la diosa egipcia de la guerra y se representa con cuerpo de mujer y cabeza de leona. Su poder y su ira eran terribles, así como su capacidad destructora. 
Y no podemos olvidar a las Amazonas, doncellas guerreras armadas, adoradoras de Artemisa en la mitología griega. Así mismo, las Valquirias en la tradición nórdica, eran valientes deidades guerreras al servicio de Odín, que luchaban contra los héroes militares, eligiendo a quienes salvar y a quienes dar la muerte. Ambas figuras representan el símbolo de la mujer fuerte e independiente en contraste con el estereotipo convencional de las sociedades patriarcales donde la debilidad y pasividad femeninas contrastan con la valentía y coraje del hombre.

Dentro de la mitología cinematográfica de la sociedad contemporánea existen algunas heroínas guerreras que imitan comportamientos violentos con rasgos tradicionales masculinos como la teniente Ellen Ripley (Sigourney Weaver), en Alien, el octavo pasajero (Ridley Scott, 1979), una de las primeras heroínas hollywoodienses; Sarah Connor (Linda Hamilton) en Terminator (James Cameron, 1984); Nikita (Anne Parillaud) en Nikita, dura de matar (Luc Besson, 1990); Catwoman, interpretada por Michelle Pfeiffer en Batman Returns, (Tim Burton, 1992) o por Halle Berry (Pitof, 2004); Lara Croft -Angelina Jolie- en Lara Croft Tomb Raider (Simon West 2001) o en Lara Croft Tomb Raider: La cuna de la vida (Jan de Bont, 2003); la vengativa Beatrix Kiddo, representada por Uma Thurman en Kill Bill de Quentin Tarantino (2003) o la despiadada agente secreto Charly Baltimore de Memoria Letal (1996), una Geena Davis dirigida por Renny Harlin justamente después de La isla de las cabezas cortadas. Por último, no podemos dejar de citar a Thelma y Louise (de nuevo Geena Davis y Susan Sarandon) que en el filme que Ridley Scott estrenó en 1991, reflejan el ansia de libertad y la búsqueda de aventuras tan habitual en el imaginario pirata.

\section{Mujeres piratas en el cine}

Las películas sobre piratas pueden ser consideradas como un subgénero propio dentro del cine de aventuras, puesto que cuentan con varias características definitorias tales como ciertos escenarios (la presencia absoluta del mar y los navíos, las islas del tesoro, las guaridas secretas), determinadas acciones (la búsqueda, el motín, el abordaje) y una galería de personajes con rasgos definitorios (patas de palo, parches en el ojo, garfios en la mano). La figura del pirata, en su vertiente heroica, cómica o sanguinaria, viene a ser un reflejo de la libertad total, de unos valores propios y de una vida ligada a la acción y la aventura. Por estos motivos, el cine de piratas ha fascinado desde sus inicios a 
jóvenes y adolescentes que encuentran en dichas películas la posibilidad de evadirse y entretenerse.

El papel que tradicionalmente ha representado la mujer en este subgénero del cine es el de un mero objeto. Un objeto bonito y hermoso al que mirar, un objeto tierno y delicado al que proteger, un objeto agresivo y seductor al que conquistar. No obstante, es posible encontrar ejemplos de personajes femeninos que desafían estas convenciones genéricas para constituirse en sujetos capaz de adoptar sus propias decisiones y luchar al mismo nivel que el hombre. Tomemos por ejemplo El pirata y la dama (Mitchell Leiden, 1944), película basada en una novela de Daphne du Maurier en la que Dona (interpretada por Joan Fontaine), una mujer inglesa de alta posición, se enamora del apuesto pirata francés Aubrey (Arturo de Córdova). Impulsada por los encantos del corsario, Dona abandona a su marido para embarcarse en el navío del pirata vestida como un chico de la tripulación. El romance no tarda en florecer y, tras una serie de peripecias, es la propia Dona quien libera al pirata cuando es capturado. El hecho de que Dona deje a su esposo es altamente significativo puesto que, según Mary Ann Doane, en los films de Hollywood de los años 40, la mujer que atenta contra el matrimonio y sigue sus deseos es severamente castigada (1987, 120). Esto no ocurre en El pirata y la dama, donde la protagonista se deja llevar por sus apetencias sexuales y sus ansias de libertad.

En otros films la mujer aparece plenamente integrada en el oficio de la piratería y ocupando los rangos más altos dentro de la jerarquía de mando. Se demuestra que el personaje femenino puede realizar las mismas acciones que el hombre (luchar, dirigir un navío, abordar, asesinar) pero es constantemente cuestionada por su naturaleza femenina. En La mujer pirata (Jacques Tourneur, 1951), Jean Peters interpreta a la capitana Providence y recalca en varias ocasiones que ella no es una dama ni quiere ser tratada como tal. De hecho, afirma que su nombre es "Capitán”, renegando del de Anne o cualquier otro que señale su condición femenina. Mientras tanto, Prudence "Spitfire" Stevens, interpretada por Maureen O'Hara en La isla de los corsarios (George Sherman, 1952), combina todo el aplomo y determinación de una mujer que se ha abierto camino por sí misma hasta convertirse en una capitana pirata con cierta feminidad. De hecho, está atraída por cómo visten y actúan las damas de alta cuna. Por 
tanto, podemos señalar que la alternancia entre actitudes (y ropas) masculinas y femeninas es una constante en la mujer pirata del cine.

Resulta necesario señalar que muchas de las mujeres piratas que encontramos en los filmes de los años 50 y 60 acceden al oficio o lo ejercen gracias a la protección del hombre, ya sea en el papel de camarada o amante. La figura del padre pirata es muy habitual y son varios los films en los que la hija de un gran corsario decide seguir sus pasos. Tomemos como ejemplo Jolanda, la figlia del Corsaro Nero (Mario Soldati, 1952), basada en la novela de Emilio Salgari. En esta película la sueca Mary Britt interpreta a Yolanda, la hija y heredera del Corsario Negro que vuelve al Caribe para reclamar su puesto como sucesora. Cuando Yolanda es secuestrada, los piratas que forman la tripulación de su padre acudirán en su rescate orgullosos de servirla. En el caso de La tigre dei sette mari (Luigi Capuano, 1963) observamos como el pirata Tigre, cansado ya de su vida en alta mar, decide dejar los mandos de su navío. Desgraciadamente solo cuenta con su hija Consuelo (Gianna Maria Canale) como heredera, por lo que promete ceder el puesto de capitán a aquel de sus hombres que resulte victorioso en un desafío. Para sorpresa de todos, Consuelo se alza con la victoria y se convierte en la nueva capitana del barco. Así pues, la mujer pirata debe demostrar su valía en todo momento a pesar de contar con el apoyo y protección de sus aliados.

Más allá de las fuentes literarias y los guiones cinematográficos, el cine de piratas ha sabido bucear en la historia en busca del rastro de auténticos marinos que ejercieron la piratería. Como no podía ser de otra forma, las mujeres piratas históricas han visto recreadas sus aventuras en distintos films. La pirata de origen inglés Mary Read, que navegó los mares del Caribe a principios del siglo XVIII, es interpretada por Lisa Gastoni en Le avventure di Mary Read (Umberto Lenzi, 1961). En dicho film, Mary es una mujer que se viste de hombre para robar joyas y termina formando parte de la tripulación del pirata Poof. Cuando el pirata muere, Mary asume el control del barco puesto que es el único "hombre" al que todos los piratas respetan. La figura de Anne Bonny, mujer pirata de origen irlandés contemporánea de Mary Read que también se vistió de hombre para entrar en una tripulación pirata, ha sido igualmente adaptada por el cine. En The Spanish main (Frank Borzage, 1945), Binnie Barnes se encarga de interpretar a esta pirata histórica que también inspiró el personaje de Anne en La mujer pirata. A pesar de que históricamente la piratería ha sido vista como un oficio de 
hombres, estos dos casos son ejemplos de la participación de la mujer en tales actividades. Aún así, existieron muchas mujeres piratas más a las que la historia y el cine aún no han prestado la atención que merecen.

A partir de finales de los años 60, el cine de piratas como subgénero agotó todas sus fórmulas y fue perdiendo el interés del público. Ciertas películas supusieron intentos aislados que pretendieron, sin éxito, devolverle su vitalidad. Debemos señalar que algunos de los más recientes de estos films sitúan a la mujer pirata como protagonista. En La isla de las Cabezas Cortadas (Renny Harlin, 1995), Geena Davis desempeña el papel de Morgan Adams, una mujer pirata en busca del mapa del tesoro que debe ganarse la confianza de su escéptica tripulación. El film cuenta con numerosas secuencias de acción que, en la mayor parte de las ocasiones, fueron interpretadas por la propia Geena Davis. Pese a lo abultado del presupuesto, la película fue un fracaso comercial. Por su parte, en Cantando dietro $i$ paraventi (Ermanno Olmi, 2003) asistimos a la narración de un cuento chino de piratas en el que la Viuda Ching (Jun Ichikawa) busca venganza por la muerte de su marido.

Recientemente, la saga Piratas del Caribe (Gore Verbinski, 2003, 2006,2007) ha conseguido un gran éxito. A pesar de que el protagonismo de los films cae sobre todo en personajes masculinos, resulta interesante destacar la evolución de Elizabeth Swann (Keira Knightley). Si en la primera película interpretaba el papel de dama a la que rescatar, vistiendo ajustados corsés y vestidos, en los siguientes films su carácter va evolucionando, al igual que su vestuario. Finalmente se convierte en un gran capitán pirata, capaz de luchar con habilidad pero sin olvidar su lado femenino.

Pese a los ejemplos señalados en estas páginas, el papel de la mujer en el cine de piratas es ciertamente reducido. Aún quedan grandes huecos que explorar y desarrollar como la realización de un film de estas características por una mujer directora, la representación de mujeres piratas homosexuales o en el rol de madre, e incluso la percepción de la audiencia de la mujer pirata.

\section{Male impersonation en la mujer pirata cinematográfica}

Travestismo es, según los diccionarios y etimológicamente, el acto de vestir ropas del sexo contrario: nada más simple sobre el papel ni nada más complejo desde el punto de vista social. Aunque ese cambio de ropa puede ser sólo un disfraz, lo cierto es que en la 
actualidad hablar de travestismo es hacer referencia la problema de la identidad sexual. No se trata del simple placer del disfraz por un día sino de la conformación identitaria de uno mismo, lo cual atañe a la sexualidad pero también al género, entendido como lo hacen la teoría feminista y la teoría queer, separando el concepto de sexo físico del concepto de sexo sentido o practicado. En cualquier caso, siempre implica el uso de apariencia física del sexo contrario al que se posee o con el que se nació. Pero, la apropiación de la ropa "del otro" es también el uso de todo el conjunto de elementos que rodea la apariencia externa social de ese "otro", es decir, sus roles, sus ademanes, sus rasgos psicológicos, su comportamiento. La forma en que vestimos desde la perspectiva antropológica y psicoanalítica se considera síntoma de la idea que queremos que la sociedad reciba de nosotros mismos; es un texto que emitimos a diario y que trasluce nuestra personalidad e incluso nuestro estado anímico. Y nada de ello se deja traslucir en el travestismo femenino de la mujer pirata en el cine hollywoodiense. En realidad, ni en mujeres ni en hombres, piratas o no. En otras cinematografías nacionales la presencia del personaje travestido es mucho más abundante y rica en matices que en la norteamericana, mucho más conservadora. Lo masculino es propio de varón y lo femenino es propio de hembra. La excepción de esta máxima es lo que plantea problemas en la combinación de elementos a la hora de crear un travestimiento. En caso de las mujeres piratas cinematográficas no sucede, porque cuando se hace es sencillamente un disfraz, lo cual, desde el punto de vista de la teoría fílmica feminista o la teoría queer sería un uso del travestismo calificable de intrascendente y hasta indigno por el matiz patriarcal que conlleva. Y casi un insulto a mujeres reales que lo hicieron como posición vital y no sólo por supervivencia, que también tiene su mérito. Así opina también Gutiérrez (2007) refiriéndose a los roles femeninos travestidos en literatura:

"El acudir a tácticas de enmascaramiento corporal apoyadas en la indumentaria típica del otro sexo con vistas a eludir el guión cultural fijado por la vigilante sociedad androcéntrica al cuerpo femenino ha sido uno de los remedios perseguidos por algunas. Modelo éste al que se acogieron quienes, a riesgo de ser descubiertas y castigadas por haber rebasado los límites admitidos, optaron por transgredir las normas del decoro, la decencia y la conducta social establecida en sus lugares de procedencia. La adopción del traje de varón, como artimaña y salvoconducto por medio del cual la mujer enemiga del statu quo ha podido gozar de privilegios reservados a los ostentadores del discurso falogocéntrico, o incluso dar rienda suelta a unos impulsos poco "femeninos" que no responden ni al papel adjudicado por los convencionalismos sociales y morales de su entorno, ni a los hábitos vestimentarios que la sociedad le ha obligado a seguir desde la infancia, ni tan siquiera a las características 
"naturales" que se le han venido atribuyendo, desestabiliza el muro de contención elevado entre los códigos artificiales adheridos al machismo de determinadas culturas y lo innato o perteneciente a los deseos individuales. No obstante, frente a las ganancias de libertad que el travestismo parece augurar, algo engañoso destila de semejante práctica, pues en la medida en que se oculta tras la imagen tropológica del Otro, y al emular la morfología de la autoridad masculina, la mujer no lleva hasta sus últimas consecuencias, con la radicalidad y el escozor que serían precisos, la definitiva reacción que desbancaría -simbólica y materialmente- las odiosas leyes del patriarcado. Con su mimetizante treta, al plegarse a los designios de la simulación, la mujer parece conformarse, todo lo más, con remover de manera tangencial y sibilina los cimientos de la maquinaria subyugante que la aprisiona, pero sin salirse verdaderamente de los aparatos ideológicos institucionalizados en los que se halla inmersa; por lo tanto, no llega a consumar una auténtica revolución”.

Y el cine, por supuesto, no se ha sustraído de personajes travestidos de un modo que en absoluto recoge la complejidad del hecho real. El travestismo en cine, lejos de convertirse, salvo excepciones, en la reivindicación de un estado de inquietud hacia el sexo de nacimiento y un deseo de revisión sobre el género, se instaura como travestismo funcional: se ejerce para conseguir algo que el personaje no puede si conserva su aspecto sexual original. Incluso pueden encontrarse diferencias cuando quien se traviste es el hombre o la mujer. Tal como afirma Paula Rodríguez Marino (2002): “Los filmes que utilizan el recurso del travestismo tomaron del burlesque la inversión de los límites entre los géneros sexuales a través de la vestimenta cruzada (mujeres caracterizadas como hombres y viceversa). El burlesque y este tipo de filmes comparten una misma paradoja: transgreden y al mismo tiempo reordenan los valores sociales. Es un movimiento de ruptura que se autolimita y termina reforzando el orden establecido". Hay un menor número de mujeres travestidas de hombre que hombres de mujeres, y mientras éstas optan por la reducción de la gestualidad y la actuación hiperbólica propia en la cultura occidental del comportamiento masculino, ellos lo asumen, consiguiendo un efecto cómico en sus gestos ampulosos. Lejos de ciertos personajes de Greta Garbo o Marlene Dietrich, fuertemente masculinizados, las piratas cinematográficas, aunque guerreras, pueden llegar a endulzar sus apariencias, puesto que todas terminan comportándose como mujeres enamoradas al ser incluidas en plots de romances. $\mathrm{Ni}$ siquiera llegan a la categoría de heroínas que se hacen pasar por hombres y mantienen con dificultad ese rol y apariencia por causas nobles, al estilo Mulán (por salvar el honor de la familia) o Ella es el chico (para poder jugar al fútbol) o Shakespeare enamorado 
(para poder interpretar), Víctor o Victoria (para poder trabajar), Yentl (para poder estudiar), etc. 3

La apariencia de las mujeres piratas reales según la iconografía clásica las presenta bajo el estereotipo de la vestimenta masculina, así aparecen en la imaginería de las artes plásticas: con gesto fiero y amenazante, empuñando armas, luchando... Rara es la representación de alguna de ellas vestida de mujer. Anne Bonny vestía ropas masculinas pero se sabía que era mujer. Ella misma se encontró en su vida con Mary Read que se hacía pasar de joven por Mark Read, por hombre. La primera de ellas es representada mostrando un pecho a un enemigo abatido, en ademán de ridiculizarlo además de vencerlo al saberse dominado por una mujer. La mayoría de las piratas reales vestían de hombre y no ocultaban su condición femenina aunque en alguna ocasión hasta ganarse el respeto de los hombres tuvieran que hacerlo. Algunas casadas, con hijos, viudas, poseían unos perfiles de mujer complejos que no se han visto reflejados adecuadamente en el cine, que se ha decantado por reproducir el tópico: una mujer vestida de hombre y masculina de comportamiento externo pero mujer en el interior aunque contraste en ademanes y educación y vestimenta con otras mujeres de este mundo de hombres: prostitutas, taberneras o damiselas en apuros. Grace O'Malley es la que aparece en un grabado vestida de mujer en el momento en que ella y la reina Isabel I se entrevistan. Conforme ha ido avanzando el siglo XX la mujer pirata ha sido representada icónicamente vestida de hombre pero explotando parte de su anatomía y provocando morbo sensual, como afirma Stanley (1996), the realities of these women pirates' lives have been lost in a murky fog of sexual and racial preconceptions.

El travestismo de la mujer pirata del cine es una cuestión de estética y comportamiento masculinos en cuerpos femeninos, un comportamiento gestual más que emocional, en tanto que todas ellas obran en algún momento por amor y protagonizan una subtrama amorosa heterosexual. En ninguna de las mujeres piratas filmadas aparece un atisbo de uno de los tabúes femeninos del cine: la homosexualidad y el suicidio, cuando es sabido que algunas mujeres piratas fueron lesbianas y una de ellas incluso se llegó a suicidarse. Como adornos morbosos en el cine no representan conflicto en la mecánica del 
travestismo que suele jugar con los conceptos de mimesis, parodia o pastiche: ni siquiera entran en este tipo de conflicto con sus compañeros piratas hombres. Y hay una clara diferenciación entre las acciones que desarrollan ejerciendo y vistiendo de mujer y vistiendo de hombre. Tanto en La mujer pirata, como en Piratas del Caribe o La isla de las cabezas cortadas, por poner ejemplos, estas guerreras marinas se visten de mujer para secuencias de seducción o para hacer uso de artimañas femeninas y conseguir lo que desean: una información, una liberación, una escapada. La mujer pirata supuestamente recrea la vida de Ann Bonny, la más famosa pirata de las Bahamas. Es capitán de su barco, vela por el bienestar de sus hombres y lucha como y con ellos. Aparece vestida de hombre pero sin ocultar su realidad de mujer. Sus ropas son las propias del marinero de la época, sucia la mayoría de las veces, otras ensangrentada, pero va mucho más ceñida y escotada que el resto de la tripulación y aunque no aparece maquillada sí tiene pelo largo relativamente bien peinado y aros grandes al estilo femenino. Su travestismo no es real, ni simulado, supone la utilización de ropas masculinas para igual su imagen y para sentirse cómoda. El mismo caso sucede en $L a$ isla de las cabezas cortadas, donde se explota mucho más la condición femenina al mostrar la anatomía de Gena Davis con mayor profusión, en este caso con un realismo superior al aparecer más desaliñada y acompañada por un mono pirata al hombro. Esta última película no pierde la oportunidad de hacerla exhibirse vestida elegantemente de mujer de época, peinada, maquillada y con todos los afeites necesarios. La apariencia tosca y falsamente masculina de la película de la década de los 50 se suaviza en la de la década de los 90 con esta pirata Morgan Adams, resultando menos ridícula la recreación del personaje. El caso de Piratas del Caribe es diferente, pues es el que manifiesta un intento de travestimiento por necesidad y ocultamiento del sexo real por parte del personaje. Elizabeth Swann, transformada de dama a pirata por amor, comienza su andadura vestida de hombre y haciéndose pasar por jovenzuelo para no levantar sospechas, por miedo ante la fiereza de este mundo masculino despiadado donde peligra sin duda la integridad físico-sexual de una mujer. Una vez descubierta, continúa usando ropas masculinas por comodidad para las acciones arriesgadas que emprende, en las que un traje con polletón puede ser un grave inconveniente en la lucha. En definitiva no son mujeres travestidas, son mujeres camaradas que ejercen una mímesis exterior masculinizante, no tanto por supervivencia como por comodidad.

\section{Masculinidad y feminidad de la mujer pirata en el cine}


La estela del feminismo se ha dejado sentir con gran impacto en las teorías y críticas cinematográficas desde que hace ya más de una treintena apareciera la primera revista feminista de cine, Women and Film, en los EE.UU y Marjorie Rosen publicara "Popcorn Venus" a modo de texto fundador. Los enfoques son amplios y variados, bifurcándose en dos ramas principales: la representación de la mujer en el discurso cinematográfico y la construcción/función de la espectadora. El tema que aquí nos ocupa tiene que ver con el primero de ellos, la mujer (pirata) en el relato cinematográfico. Colaizzi (2001) apunta que el tratamiento de las mujeres en el discurso fílmico corresponde a los estereotipos más tradicionales de la feminidad: son, fundamentalmente, objetos de deseo, adoración o violencia, sujetos pasivos, castigados si se atreven a plantearse una actitud activa, a desear o cuestionar el modelo hegemónico de "ángel del hogar”, y atrapados por la imposibilidad de salir de las figuras complementarias y yuxtapuestas de madre/femme fatale, virgen/puta. Pero existen otro tipo de mujeres alejadas de estos estereotipos del cine clásico patriarcal que algunos han tenido el (mal) gusto de denominar "mujer fálica”, un personaje fuerte, que no necesita a los hombres y que sabe utilizar la violencia para conseguir sus fines (Gómez, 2001), aquella que adquiere roles masculinos y niega su propia feminidad (González, 2006).

Guarinos (2007:107) contempla una tipología de los estereotípicos cinematográfico más comunes: la chica buena, el ángel, la virgen, la beata/solterona, la chica mala, la femme fatale o vamp, madre castradora madrastra, madre del monstruo, madre sin hijos, la Cenincienta, la villana, la dominatrix, entre otras, siendo la descripción de guerrera la que más se adecua a la condición de mujer pirata retratada por la industria cinematográfica; así la define Guarinos: mujeres por lo general de corte histórico mítico, al estilo de las amazonas que anteponen la lucha a otras facetas personales. Suelen ser también muy atractivas y renunciar a los hombres o renunciar a su condición de guerreras por un hombre. Anne -el Capitán Providence- (Jean Peters) en La mujer pirata (Jacques Tourneur, 1951), Prudence (Maureen O'Hara) en La isla de los corsarios, (George Sherman, 1952), Morgan Adams (Geena Davis) en La isla de las Cabezas Cortadas (Renny Harlin, 1995), Elizabeth Swann (Keira Knightley) en la trilogía de Piratas del Caribe (Gore Verbinski, 2003, 2006,2007), son alguna de las más importantes mujeres piratas retratadas por el aparato cinematográfico. Pero, ¿qué rasgos 
masculinos adquieren las mujeres piratas en la gran pantalla?, ¿qué rasgos femeninos conservan?

Cabral y García (1993) establecen una dicotomía de los modelos de masculinidad y feminidad congelados y cristalizados en estereotipos sexuales y pautas de comportamiento. Si analizamos el caso de estas mujeres piratas, observamos que la tendencia es a la masculinización (con valores aceptados occidentalmente como positivos), lo que en ningún caso significa la pérdida de lo femenino (valores negativos o no tan positivos). Así, las piratas de celuloide son fuertes (luchan como cualquier otro pirata), inteligentes (descifran mapas y tienden trampas), activas, agresivas (amenazan y extorsionan) y decididas, pero también son bellas, emocionales, intuitivas y coquetas (cuando un apuesto galán se cruza en sus caminos). Otros rasgos tradicionalmente masculinos que manifiestan las mujeres piratas en el cine tienen que ver con los roles instrumentales que desempeñan: luchar, vencer, controlar, conquistar, expresar su sexualidad; pero también se sacrifican, se dejan conquistar, son fieles y seducen. A este respecto, Guarinos (op.cit: 104) acierta al manifestar que la masculinización del cine patriarcal comercial deriva en la creación de otro estereotipo más que añadir a los ya tradicionales.

No existe un modelo que defina unitariamente a la mujer pirata, no hay una mujer pirata, hay mujeres piratas. No en vano constan elementos comunes: normalmente la mujer pirata no pertenece a la masa difuminada de la tripulación (Ana María -Zoe Saldana-, la pirata negra de Piratas del Caribe I que abofetea dos veces seguidas a Jack Sparrow antes de embarcarse para luchar junto a él es la excepción que confirma la regla) sino que adquiere, desde un primer momento (Anne en La mujer pirata) o tras una evolución de tres películas (Elisabeth en la trilogía de Piratas del Caribe) el rango de capitana (o capitán, como se hace llamar Anne). Son astutas, inteligente, luchadoras, competitivas y toman decisiones que generalmente son respetadas y llevadas a cabo por sus subordinados.

Piratas, pero mujeres, siguen encasilladas en el halo del amor y el romanticismo. Unas estarán dispuestas a darlo todo por amor, incluso la vida (Anne), otras sólo su mitad del tesoro (Morgan). Sea como fuere, la pasión, la traición, los celos y las reconciliaciones forman parte de las tramas de estos personajes que siempre se cruzan con un apuesto 
galán: el impostor Capitan Pierre (Louis Jourdan) en La mujer pirata, el pícaro Brian Hawke (Errol Flynn) en La isla de los corsarios, el honrado pero ladrón William Shaw (Matthew Modine) en La isla de las cabezas cortadas o apuesto y fiel William Turner (Orlando Bloom) en Piratas del Caribe. De nuevo se presenta aquí la dualidad entre lo femenino y lo masculino, pues si bien en algunos momentos las chicas son las seductoras (cuando Hawke va a besar a Prudence, ella le saca una pistola y le aclara que ella besa cuando quiere besar; Morgan ordena al señor Shaw que vaya a su camarote de inmediato con claras connotaciones sexuales), en otros se presentan como mujeres débiles a las que el hombre puede dominar, ya sea físicamente (el Capitán Roc Brasiliano -Anthony Quinn- besa por la fuerza a Prudence) o sentimentalmente (el desengaño de Anne la lleva a un estado depresivo que la empuja a dejar de luchar por todo aquello por lo que lo había hecho hasta ahora, buques, corsarios, tesoros, a saber, el mundo de la piratería).

Por otro lado Francesco Casetti (1994: 253 y ss) enumera una serie de puntos que tienen que ver con la narrativa de la mujer:

- Son estereotipos monocordes, sin matices.

- No producen narratividad.

- Son imagen y se les recuerda físicamente, como un elemento escenográfico.

- Son fijas y eternas como los mitos.

- Permanecen marginadas fuera de la historia y elevadas a la glorificación como fetiches.

- Son objeto de intercambio, cuyo valor es decidido por los hombres.

- Se habla de ella pero ella no habla, sólo parlotea.

- Son deseadas, pero no desean.

- No actúan, son manejadas.

- No miran, son miradas.

- Sucumben en el fracaso si intentan rebelarse contra este sistema.

Más allá de lo masculino y lo femenino, la mujer pirata del celuloide ha conseguido romper muchas de estas barreras narrativas que le impedían ser protagonista activa del relato. Anne representa un alto grado de protagonismo, produce narratividad, no se le recuerda exclusivamente por su imagen sino por sus decisiones y actos, habla como un verdadero pirata (de forma engreída y con palabras malsonantes), actúa y desea con una pasión desbordante. También el personaje de Morgan conlleva la mayor parte del peso de la narración, siendo la verdadera protagonista de la cinta. En cambio, el personaje de 
Prudence es bastante más pasivo, pero aun con numerosos resquicios de ese personaje femenino que se deja conquistar, aporta narratividad al relato y toma parte en su progresión, eso sí, siempre superada, o al menos igualada por el personaje masculino principal. En la saga de Piratas del Caribe, el personaje de Elisabeth sufre una evolución, manteniendo siempre un papel de co-protagonista junto a Turner, sólo superados por Jack Sparrow. La aparición de los personajes femeninos en el cine ha sido reconstruida en su gran mayoría por la mirada y los deseos del hombre, en el caso de la mujer pirata también. A pesar de que se rompe con la tradición de la mujer frágil, dependiente y pasiva, mantiene, como venimos apuntando la belleza y sensualidad propias. De modo que a las mujeres no les queda más espacio que ser objeto de mirada a riesgo de no ser nada, dice González (2006) en un tono de resignación, un tono conformista que debería cambiar y evolucionar hacia otro más esperanzador y optimista.

\section{Bibliografía}

ALMODÓVAR, Miguel Ángel (2004): Armas de varón. Mujeres que se hicieron pasar por hombres, Madrid, Oberon.

ARABI, El Hassane (2005): Mujeres de Marruecos. Madrid, Clan.

BAKER, Roger (1995): Drag: A History of Female Impersonation in the Performing Arts, New York, NY University Press.

BELL-METERARAU, Rebeca (1985): Hollywood Androgyny, New York, Columbia University Press.

BORNAY, Erika (1990). Las hijas de Lilith, Madrid, Ediciones Cátedra.

CABRAL, Blanca y GARCÍA, Carmen (1999): “Masculino/Femenino... ¿Y yo?

Identidad o Identidades de Género" del I Congreso Iberoamericano de Psicología

Clínica y de Saulud, Granada, España. Online

http://www.saber.ula.ve/handle/123456789/16351 (01/03/17).

CASETTI, Francesco (1994): Teorías de cine, 1945-1990, Madrid, Cátedra.

COLAIZZI, Giulia, (2001): "El acto cinematográfico: género y texto fílmico" en Lectora, $\mathrm{n}^{\circ} 7$. Online

http://www.ub.edu/cdona/Lectora_07/1\%20Introd\%20Giulia\%20MAQ.pdf (01/03/2017).

CORDINGLY, David (2003): Mujeres en el mar. Capitanas, corsarias, esposas y rameras, Barcelona, Edhasa.

DARFÁN, Milagro (2005): “Sobre representaciones de la mujer en el cine y crítica 
feminista" en Miradas. Online

http://www.eictv.co.cu/miradas/index.php?option=com_content\&task=view\&id=538\&I temid=93 $(01 / 03 / 17)$.

DEKKER, Rudolf \& Van de Pol, Lotte (2006): La doncella quiso ser marinero.

Travestismo femenino en Europa (siglos XVII-XVIII), Madrid, Siglo XXI.

DESCHAMPS, Hubert (1956): Piratas y filibusteros. Madrid, Salvad.

DIJKSTRA, Bram (1994) Ídolos de perversidad: la imagen de la mujer en la cultura de fin de siglo, Madrid, Debate.

DOANE, Mary Ann (1987): The Desire to Desire: The Woman's Film of the 1940s.

Bloomington, Indiana University Press.

DURAND, Gilbert y VIERNE, Simone (1987): “Avant-propos” en Le mythe et le mythique. Colloque de Cerisy, París, Albin Michel.

GÓMEZ, Juan (2001): “La mujer fálica irrumpe en el cine” en El País, 22/08/2001

Online

http://www.elpais.com/articulo/revista/agosto/mujer/falica/irrumpe/cine/elpepirdv/2001 0822elpepirdv_7/Tes/ (01/03/17).

GONZÁLEZ, Noemí (2006): "La imagen virtual hecha carne: Alice en Residente Evil" en Mujeres, espacio y poder. Sevilla, Arcibel Editores.

GOSSE, Philip (2003): Quién es quién en la piratería: hechos singulares de las vidas y muertes de los piratas y bucaneros. Sevilla, Renacimiento.

GRIMAL, Pierre (1981): Diccionario de mitología griega y romana, Barcelona, Paidós. GUARINOS, Virginia (2007): "Mujeres en Proyección. la Mujer en el Cine” en La Mirada de las Mujeres en la Sociedad de la Información, Madrid, Siranda Editorial. GUTIÉRREZ, José Ismael (2007): "Pieles que importan. Sobre la mujer (in)vestida de varón”, en Speculo, n³6. Online http://www.ucm.es/info/especulo/numero36/travmuje.html (22/02/17).

HALBERSTAM, Judith (1998): Female Masculinity, Durham, Duke University Press. HUSAIN, Shahrukh (1997): La diosa. Creación, fertilidad y abundancia. Mitos y arquetipos femeninos, Köln, Evergreen.

IGLESIAS, Norma (2003): "Redefiniendo lo femenino en el cine", en Texturas urbanas: Comunicación y cultura, México, Fundación Manuel Buendía (Universidad Iberoamericana).

LAURETIS, Teresa De (1992): Alicia ya no: Feminismo, semiótica, cine, Madrid, Cátedra. 
MORATÓ, Cristina (2007): Viajeras intrépidas y aventureras. Madrid, Random House Mondadori.

MUSNIK, Henry (2007): Las mujeres pirata. Sevilla, Renacimiento.

PÉREZ RIOJA, José Antonio (1980): Diccionario de símbolos y mitos, Madrid, Tecnos. RAMÍREZ ALVARADO, Ma del Mar (2001): Construir una imagen. Visión europea del indígena americano, Sevilla, CSIC.

RODRIGUEZ MERINO, Paula (2002): "El travestismo masculino y femenino en el cine, en Mnemocine, febrero 2002, en

http://www.mnemocine.com.br/cinema/historiatextos/paulamarino.htm (23/02/17).

SILES, Begoña (2000): “Una mirada retrospectiva: treinta años de intersección entre el feminismo y el cine" en Caleidoscopio $\mathrm{n}^{\circ} 1$.

Onlinehttp://www.uch.ceu.es/caleidoscopio/numeros/uno/ssiles2.html (01/02/2017). STANLEY, Jo, Chambers, Ann, Murray, Diane \& Wheelwright, Julie (1996): Bold in her Breeches: Women Pirates Across the Ages, London, Harper Collins.

STRAAYER, Chris (1995): "Redressing the Natural: The Temporary Transveted Filme, in Grant, Barry (Ed.): Film Reader II, Austin, University of Austin Texas Press, pp. 403-427.

VÁZQUEZ CHAMORRO, Germán (2004): Mujeres piratas, Madrid, Algaba. VV.AA. (1961): Piratas, corsarios y filibustero, Barcelona, Maucci.

VV.AA. (1987): Le mythe et le mythique. Colloque de Cerisy, París, Albin Michel.

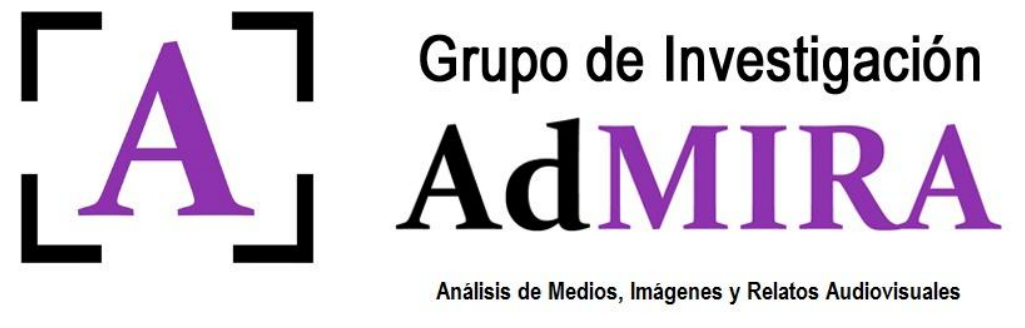

